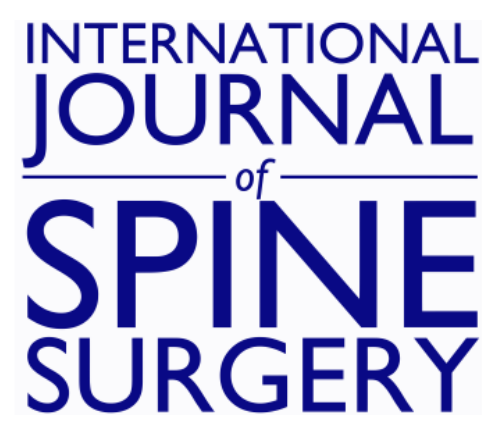

\title{
Two-Level Anterior Cervical Discectomy and Fusion Versus Cervical Disc Arthroplasty--Long-Term Evidence Update
}

Zachary H Goldstein, Barrett Boody and Rick Sasso

Int J Spine Surg 2020, 14 (s2) S36-S40

doi: https://doi.org/10.14444/7089

http://ijssurgery.com/content/14/s2/S36

This information is current as of April 25, 2023.

Email Alerts Receive free email-alerts when new articles cite this article. Sign up at:

http://ijssurgery.com/alerts 


\title{
Two-Level Anterior Cervical Discectomy and Fusion Versus Cervical Disc Arthroplasty-Long-Term Evidence Update
}

\author{
ZACHARY H GOLDSTEIN, MD, ${ }^{1}$ BARRETT BOODY, MD,${ }^{2}$ RICK SASSO, MD ${ }^{2}$ \\ ${ }^{I}$ Department of Orthopaedic Surgery, Indiana University School of Medicine, Indianapolis, Indiana, ${ }^{2}$ Indiana Spine Group, Carmel, Indiana
}

\begin{abstract}
Background: Multiple studies have highlighted the motion-sparing benefits of single-level cervical disc arthroplasty (CDA) compared with anterior cervical discectomy and fusion (ACDF). However, few studies have reviewed multilevel ACDF versus CDA. Several recent studies have midterm and even long-term data available comparing 2-level ACDF versus CDA.

Methods: We reviewed 3 reports from 2 large randomized, prospective Food and Drug Administration investigational drug exemption trials looking at 2-level CDA versus ACDF, which provide the bulk of the available midterm to long-term, high-level evidence for the topic. We also present several smaller and/or shorter-term studies.

Results: One 5-year study showed that, while both CDA and ACDF showed significant improvement in patientreported outcome scores, CDA demonstrated greater improvement in Neck Disability Index (NDI) scores than ACDF (mean $=-37$ versus mean $=-28, P=.0003)$, were more likely to be satisfied $(96.4 \%$ versus $89.5 \%, P=.04)$, had fewer secondary surgeries ( $4 \%$ versus $16.2 \%, P=.0003)$, had fewer adjacent level reoperations $(3.1 \%$ versus $11.4 \%)$, and developed less adjacent segment degeneration $(50.7 \%$ versus $90.5 \%, P<.0001)$. Adverse events occurred more frequently with $\mathrm{ACDF}(8.6 \%$ versus $4.4 \%)$.

Similarly, Lanman et al [Lanman TH, Burkus JK, Dryer RG, Gornet MF, McConnell J, Hodges SD. Long-term clinical and radiographic outcomes of the Prestige LP artificial cervical disc replacement at 2 levels: results from a prospective randomized controlled clinical trial. J Neurosurg Spine. 2017;27(1):7-19] showed that, at 7 years, while both groups demonstrated improvement in patient-reported outcomes, CDA had greater improvement in regard to NDI, neck pain, and Short Form (36) Physical Component Summary scores (each $P<.001$ ), had higher rates of satisfaction (94.8\% versus $92.6 \%)$, had lower rate of secondary surgery at treated levels $(4.2 \%$ versus $14.7 \%)$, and had a lower, albeit not statistically significant, rate of secondary surgeries at adjacent levels $(6.5 \%$ versus $12.5 \%)$. Adverse events were more common with ACDF (7.2\% versus $3.2 \%)$.

More recently, Gornet et al [Gornet MF, Lanman TH, Burkus JK, et al. Two-level cervical disc arthroplasty versus anterior cervical discectomy and fusion: 10-year outcomes of a prospective, randomized investigational device exemption clinical trial. J Neurosurg Spine. 2019;31:508-518.] in 2019 reported 10-year data from the same clinical trial as the Lanman et al report comparing 2-level CDA (209 patients) versus ACDF (188 patients). With $>84 \%$ follow-up for both groups at 10 years, they found that CDA demonstrated a statistically significantly improved rate of overall success $(84 \%$ versus $62 \%)$ as compared with ACDF. Greater improvements were seen in several other outcome measures for CDA, including NDI, neurological success, and neck pain scores. The CDA group had a lower rate of serious implant-related adverse events and demonstrated a lower rate of needing a secondary surgery at an adjacent level, $9 \%$ versus $18 \%$ in the ACDF group.
\end{abstract}

Conclusions: Results of 2 large randomized trials suggest similar-to-improved patient reported outcomes for multilevel CDA versus ACDF maintained out to midterm to long-term follow-up of 5-10 years, with lower rates of revision surgery at index and adjacent levels and lower rates of serious adverse device-related events.

Level of Evidence: 5.

Clinical Relevance: Comparison of the safety and efficacy of multi-level cervical disc arthroplasty and cervical discectomy and fusion.

Special Issue-Cervical Spine

Keywords: cervical, disc, arthroplasty, anterior, discectomy, fusion, 2-level, multilevel

\section{INTRODUCTION}

Multiple studies have highlighted the effectiveness of cervical disc arthroplasty (CDA) for successful management of cervical radiculopathy and myelopathy, as well as the biomechanical advantages of motion-sparing technology on reducing radiographic and clinically significant adjacentlevel degeneration. ${ }^{1-6}$ While a significant amount of 
literature and research have been conducted for 1level anterior cervical discectomy and fusion (ACDF) compared with CDA, few studies have reviewed multilevel ACDF versus CDA. Due to the high prevalence of patients presenting with multilevel cervical degenerative disease, several recent studies have midterm to long-term data available comparing 2-level ACDF versus CDA, helping surgeons guide clinical decision making in regard to implant selection.

\section{METHODS}

We reviewed 3 reports from 2 large randomized, prospective Food and Drug Administration (FDA)investigational device exemption trials that are available for 2-level CDA versus 2-level ACDF, which provide the bulk of the available midterm as well as long-term, high-level evidence for the topic. We also reviewed several smaller and/or shorterterm studies that have looked at 2-level CDA versus 2-level ACDF.

\section{RESULTS}

Radcliff et $\mathrm{al}^{7}$ recently published 5-year outcomes on the results of a prospective, randomized FDA IDE trial comparing 2-level CDA (Mobi-C, LDR Medical/Zimmer Biomet, Warsaw, IN) versus ACDF with corticocancellous grafts and anterior cervical plates. At 5 years, $82.7 \%$ of CDA (186 of 225 treated) and $68.6 \%$ of ACDF (72 of 105 treated) were available for follow-up. While both groups showed significant improvement in patient-reported outcome scores (visual analog scale [VAS] neck and Neck Disability Index [NDI] scores) from baseline to 5-year follow-up, the CDA group demonstrated greater improvement in NDI scores than the ACDF group $($ mean $=-37, \mathrm{SD} 20$ versus mean $=-28, \mathrm{SD}=$ $18, P=.0003)$. While both groups demonstrated high satisfaction rates with surgery, patients receiving CDA were significantly more likely to be satisfied $(96.4 \%$ versus $89.5 \%$, respectively, $P=$ .04). Furthermore, the CDA group had fewer secondary surgeries than ACDF (4\% versus $16.2 \%$, respectively, $P=.0003)$ and significantly fewer adjacent level reoperations $(11.4 \%$ versus $3.1 \%$, respectively). Significantly less radiographic adjacent segment degeneration occurred in the CDA group $(50.7 \%$ for CDA versus $90.5 \%$ for ACDF, $P$ $<.0001)$. Additionally, serious device-related adverse events occurred more frequently in ACDF patients $(8.6 \%$ ACDF versus $4.4 \%$ CDA). Radiographic fusion rates of ACDF were $90.5 \%$ at 5 years, with $8.6 \%$ of patients requiring revision surgery for symptomatic nonunion.

Similarly, Lanman et $\mathrm{l}^{8}$ recently published longterm findings for the Prestige LP (Medtronic, Minneapolis, MN) CDA versus ACDF with cortical ring allograft and Atlantis (Medtronic, Minneapolis, MN) plate. ${ }^{8}$ They reported results from 397 treated patients with up to 84 months' follow-up of a prospective, randomized FDA IDE trial. At 84 months, $73.7 \%$ (154 of 209 treated) of CDA patients and $67 \%$ (126 of 188 treated) of ACDF patients were available for follow-up. While both CDA and ACDF groups demonstrated significant improvement over baseline patient-reported outcome scores, the CDA group displayed significant improvement compared with the ACDF group in regard to NDI, neck pain, and Short Form (36) Physical Component Summary scores at 84 months (each $P<.001$ ). Similarly, both groups expressed high rates of satisfaction with surgery, with $94.8 \%$ of patients in the CDA group and $92.6 \%$ of the patients in the ACDF group reporting definitely or mostly satisfied. Furthermore, $94.8 \%$ and $89.4 \%$, respectively, said they would undergo the surgery again for the same condition. Successful fusion was reported in $92 \%$ of ACDF at 84 months, with secondary surgery at treated levels at $4.2 \%$ for CDA and $14.7 \%$ for ACDF, reaching statistical significance (likelihood ratio $=-1.29[95 \%$ confidence interval $=-2.12$ to $-0.46])$. Secondary surgeries at adjacent levels through 84 months were higher for ACDF but did not reach significance $(6.5 \%$ for $\mathrm{CDA}$ and $12.5 \%$ for ACDF). Serious adverse events classified as implant/surgical procedure associated were more common with ACDF, reporting 3.2\% for CDA and $7.2 \%$ for ACDF (likelihood ratio $=-1.19[95 \%$ $\mathrm{BCI}=-2.29$ to -0.15$])$.

More recently, Gornet et $\mathrm{al}^{9}$ reported 10-year data on this same clinical trial, comparing 2-level CDA (209 patients) versus ACDF (188 patients). ${ }^{9}$ With $>84 \%$ follow-up for both groups at 10 years, they found that CDA demonstrated a statistically significantly improved rate of overall success $(84 \%$ versus $62 \%$ ) as compared with ACDF. Greater improvements were seen in several other outcome measures for CDA, including NDI, neurological success, and neck pain scores. All other outcome measures were at least noninferior for CDA as compared with 2-level ACDF. The CDA group had 
a lower rate of serious implant-related adverse events and demonstrated a lower rate of needing a secondary surgery at an adjacent level, 9\% versus $18 \%$ in the ACDF group.

Several smaller studies have been conducted reviewing 2-level ACDF versus CDA, giving further insight into the performance of 2-level CDA outside of FDA IDE trials. However, very few studies have produced outcomes beyond the 24-month follow-up timeframe. Gao et $\mathrm{al}^{10}$ reviewed 5-year results of 24 2-level CDA (Prestige LP) versus 36 2-level ACDF with ZERO-P spacers (DePuy Spine, Raynham, MA). Both groups exhibited significant improvement in patient-reported outcomes (Japanese Orthopedic Association (JOA) score, NDI, VAS) from baseline to 5-year follow-up with no significant difference seen between groups. The loss of motion from $\mathrm{C}_{2}-7$ was significantly higher in the ACDF group from baseline to 5 years $\left(44.1^{\circ}\right.$ to $28.1^{\circ}$ for ACDF versus $51.1^{\circ}$ to $46.5^{\circ}$ for CDA, $P<.001$ ). However, no significant difference was seen in cervical lordosis maintained from baseline to 5-year follow-up between groups $\left(7.5^{\circ}\right.$ to $10.7^{\circ}$ for CDA versus $9.6^{\circ}$ to $10.0^{\circ}$ for $\mathrm{ACDF}, P=.243$ ). While higher rates of adjacent segment degeneration were seen in the ACDF group ( 8 for ACDF versus 2 for CDA), no reoperations within 5 years were performed for either group.

Multiple smaller studies have been published with approximately 24-month follow-up, with several significant studies worth discussion. Kim et $\mathrm{al}^{11}$ performed a nonrandomized, prospective cohort trial of 105 patients undergoing 1- or 2-level CDA (Bryan Disc, Medtronic Sofamor Danek, Memphis, $\mathrm{TN})$ versus ACDF with a mean follow-up of approximately 19 months. Two-level CDA was performed in 12 patients and 2-level ACDF in 28 patients. For patients undergoing 2-level procedures, all patients significantly improved their VAS and NDI scores from baseline to final follow-up with no significant difference between groups. The 2-level CDA group showed significantly improved C2-7 and functional spinal unit range of motion as well as maintenance of sagittal alignment compared with the 2-level ACDF group. Similarly, the 2-level CDA group demonstrated fewer degenerative radiographic adjacent segment changes than the 2level ACDF group $(33.33 \%$ versus $57.14 \%$, respectively).

Fay et $\mathrm{al}^{12}$ retrospectively compared 40 patients with a 2-level ACDF and 37 patients with a 2-level
CDA (Bryan Disc) with 24 months' follow-up. Both groups significantly improved patient-reported outcome scores (VAS neck, VAS arm, NDI, JOA) scores from baseline to 24-month follow-up with no significant difference between groups. All 2-level ACDFs were found to have bony fusion by 24month follow-up, and no symptomatic adjacent segment disease requiring reoperations were reported for either group within the study period. The CDA group increased the index segment postoperative range of motion $\left(20.1^{\circ}\right.$ at baseline versus $23.5^{\circ}$ at 24 months' follow-up, $P=.018$ ), while the ACDF group significantly decreased motion through the fused segments $\left(19.3^{\circ}\right.$ at baseline versus $1.6^{\circ}$ at $24-$ month follow-up, $P<.001)$.

Cheng et $\mathrm{al}^{13}$ conducted a prospective, randomized control trial with 2-year follow-up of 31 2-level CDA (Bryan Cervical Disc) versus 34 2-level ACDF with iliac crest autograft and Orion anterior cervical plate (Medtronic Sofamor Danek, Memphis, TN). No significant differences were seen in baseline demographics, and 1 2-level and 2 2-level ACDF patients did not complete final follow-up. Both groups demonstrated significant improvement in patient-reported outcomes (NDI, VASarm, VAS-neck) from baseline to 2-year follow-up $(P<.001)$. When compared between groups, 2level CDA showed significant improvements in NDI, VAS-arm, and VAS-neck compared with 2level ACDF at 24-month follow-up $(P=.023, P=$ .013 , and $P=.012$, respectively). The 2-level CDA group did not show significant change in range of motion, retaining an average of $7.9^{\circ}$ through the operative segments over 24-month follow-up $(P=$ .35). Furthermore, no neurological complications were reported in either group, and there were no device failures, spontaneous fusions, or explantations.

Hou et $\mathrm{al}^{14}$ reported 24-month follow-up on the 1- and 2-level Discover (DePuy Spine, Raynham, MA) CDA versus 1- and 2-level ACDF, with 32 and 88 patients receiving 2-level CDA and 2-level ACDF, respectively. It is important to note this cohort study used dissimilar groups, with enrolled patients with contraindications to CDA (instability, facet arthropathy, osteoporosis, etc.) placed into the ACDF group. Both groups showed significant improvement in VAS and NDI from baseline to 24-month follow-up, with no significant different between groups (VAS $P=.28$, NDI $P=.21$ ). No significant differences were reported for complica- 
tion rates $(21.9 \%$ for CDA and $29.5 \%$ for ACDF, $P$ $=4$ ), but a significant increase in radiographic changes at adjacent levels was seen for 2-level ACDF compared with 2-level CDA (15.6\% versus $42 \%$, respectively, $P=.007$ ).

\section{DISCUSSION}

The results of the 2 large randomized trials suggest similar-to-improved patient-reported outcomes for 2-level CDA versus 2-level ACDF maintained out to midterm to long-term followup of 5-10 years with lower rates of revision surgery at index and adjacent levels and lower rates of serious adverse device-related events for 2-level CDA as compared with 2-level ACDF. The results must be interpreted considering multiple sources of bias commonly found with industry-funded trials, such as publication, observer, ascertainment, and confirmation biases as well as the Hawthorne effect. Patients were not blinded to the results of treatment, and readers do not know the initial treatment preference of the patients prior to enrollment. The potential for observer, ascertainment, and confirmation bias exists with the reporting of postoperative outcomes as well as indications that lead to reoperations. Financial conflicts of interest can create publication bias, potentially limiting the publication and communication of negative results that would compromise the large industry investments in implants and trial performance. Despite the inherent biases present in these trials, these 3 studies demonstrate the highest available levels of evidence with large prospective randomized trials and supply the most robust data available for clinicians to make medical decision making.

The preponderance of available data suggests that, for proper indications as outlined in the abovementioned FDA IDE trials, 2-level CDA is a safe and effective surgical procedure for the treatment of cervical radiculopathy and/or myelopathy with comparable to improved clinical and radiographic outcomes compared with ACDF out to long-term follow-up. Until longer-term data become available, we are unable to make evidencebased conclusions on the safety or effectiveness of 2level CDA beyond 10 years.

Of note, author \#3 receives royalties from a company involved in the manufacturing of a device examined in this study.

\section{REFERENCES}

1. Galbusera F, Bellini CM, Brayda-Bruno M, Fornari M. Biomechanical studies on cervical total disc arthroplasty: a literature review. Clin Biomech (Bristol, Avon). 2008;23(9):1095-1104. doi:10.1016/j.clinbiomech.2008.06.002

2. Zhong ZM, Zhu SY, Zhuang JS, Wu Q, Chen JT. Reoperation after cervical disc arthroplasty versus anterior cervical discectomy and fusion: a meta-analysis. Clin Orthop Relat Res. 2016;474(5):1307-1316. doi:10.1007/s11999-0164707-5

3. Dong L, Xu Z, Chen X, et al. The change of adjacent segment after cervical disc arthroplasty compared with anterior cervical discectomy and fusion: a meta-analysis of randomized controlled trials. Spine J. 2017;17(10):1549-1558. doi:10.1016/j. spinee.2017.06.010

4. Zhu Y, Zhang B, Liu H, Wu Y, Zhu Q. Cervical disc arthroplasty versus anterior cervical discectomy and fusion for incidence of symptomatic adjacent segment disease: a metaanalysis of prospective randomized controlled trials. Spine. 2016;41(19):1493-1502. doi: 10.1097/BRS.0000000000001537

5. Zarkadis NJ, Cleveland AW, Kusnezov NA, Dunn JC, Caram PM, Herzog JP. Outcomes following multilevel cervical disc arthroplasty in the young active population. Mil Med. 2017;182(3):e1790-e1794. doi:10.7205/MILMED-D-16-00085

6. Cody JP, Kang DG, Tracey RW, Wagner SC, Rosner MK, Lehman RA Jr. Outcomes following cervical disc arthroplasty: a retrospective review. J Clin Neurosci. 2014;21(11):1901-1904. doi:10.1016/j.jocn.2014.05.008

7. Radcliff K, Coric D, Albert T. Five-year clinical results of cervical total disc replacement compared with anterior discectomy and fusion for treatment of 2-level symptomatic degenerative disc disease: a prospective, randomized, controlled, multicenter investigational device exemption clinical trial. J Neurosurg Spine. 2016;25(2):213-224. doi:10.3171/2015. 12.SPINE15824

8. Lanman TH, Burkus JK, Dryer RG, Gornet MF, McConnell J, Hodges SD. Long-term clinical and radiographic outcomes of the Prestige LP artificial cervical disc replacement at 2 levels: results from a prospective randomized controlled clinical trial. J Neurosurg Spine. 2017;27(1):7-19. doi:10.3171/ 2016.11.SPINE16746

9. Gornet MF, Lanman TH, Burkus JK, et al. Two-level cervical disc arthroplasty versus anterior cervical discectomy and fusion: 10-year outcomes of a prospective, randomized investigational device exemption clinical trial. J Neurosurg Spine. 2019;31:508-518. doi:10.3171/2019.4.SPINE19157

10. Gao X, Yang Y, Liu H, et al. A comparison of cervical disc arthroplasty and anterior cervical discectomy and fusion in patients with two-level cervical degenerative disc disease: 5-year follow-up results. World Neurosurg. 2018;122:e1083-e1089. doi:10.1016/j.wneu.2018.10.231

11. Kim SW, Limson MA, Kim SB, et al. Comparison of radiographic changes after ACDF versus Bryan disc arthroplasty in single and bi-level cases. Eur Spine J. 2009;18(2):218231. doi:10.1007/s00586-008-0854-z

12. Fay LY, Huang WC, Tsai TY, et al. Differences between arthroplasty and anterior cervical fusion in two-level cervical degenerative disc disease. Eur Spine J. 2014;23(3):627-634. doi: 10.1007/s00586-013-3123-8

13. Cheng L, Nie L, Zhang L, Hou Y. Fusion versus Bryan 
Cervical Disc in two-level cervical disc disease: a prospective, randomised study. Int Orthop. 2009;33(5):1347-1351. doi:10. 1007/s00264-008-0655-3

14. Hou Y, Liu Y, Yuan W, et al. Cervical kinematics and radiological changes after Discover artificial disc replacement versus fusion. Spine J. 2014;14(6):867-877. doi:10.1016/j.spinee. 2013.07.432

Disclosures and COI: Z.H.G.: None. B.B.: Personal fees from Innovative Surgical Designs, outside the submitted work. R.S.: Personal fees from Medtronic, outside the submitted work.

Corresponding Author: Zachary Goldstein,
MD, Department of Orthopaedic Surgery, Indiana University School of Medicine, 720 Eskenazi Ave, Fifth-Third Building, Room F2-163, Indianapolis, IN 46202. Phone: (224) 944-7635; Fax: (317) 8800553; Email: zhgoldst@iupui.edu.

Published 30 September 2020

This manuscript is generously published free of charge by ISASS, the International Society for the Advancement of Spine Surgery. Copyright (c) 2020 ISASS. To see more or order reprints or permissions, see http://ijssurgery.com. 